\title{
Diagnostic Investigation of Hydro Electric Project Made Easy with Remote Operated Vehicle
}

\author{
Alex Varughese*, Hari Dev, Sohan Lal Gupta \\ Engineering Geophysics Division, Central Soil and Materials Research Station, New Delhi, India \\ Email address: \\ alexvarughese@gmail.com (A. Varughese) \\ ${ }^{*}$ Corresponding author
}

To cite this article:

Alex Varughese, Hari Dev, Sohan Lal Gupta. Diagnostic Investigation of Hydro Electric Project Made Easy with Remote Operated Vehicle. American Journal of Civil Engineering. Vol. 6, No. 1, 2018, pp. 1-4. doi: 10.11648/j.ajce.20180601.11

Received: September 13, 2017; Accepted: October 11, 2017; Published: November 21, 2017

\begin{abstract}
Regular safety appraisal of dam and its appurtenant structures is recommended by dam safety committees. Monitoring of dam is carried out in many ways like Visual inspections, Instrumentation, Non-Destructive Testing (NDT) and Underwater Inspection using divers, Remote Operated Vehicle (ROV) and Geophysical methods. In dealing with the safety problems during the operation, maintenance and surveillance of dams, it is essential to carefully collect process and study all available information. Underwater scanning, using ROV, is a good solution for assessment of health of submerged portion of structures. This paper presents case studies of underwater scanning of an important Hydro Electric Project using the Remote Operated Vehicle for the diagnostic investigation.
\end{abstract}

Keywords: Dam Safety, Remote Operated Vehicle, Underwater Inspection, Diagnostic Investigation, Instrumentation

\section{Introduction}

Civil engineering structures of hydel power plants such as dam, water intake, trash-racks of penstocks, etc. are usually submerged and there are few effective methods for their inspection [1]. Regular visual inspection and adequate monitoring is required for the assessment of the dam condition and for taking timely action for mitigating the same [2]. Regular safety appraisal of dam and its appurtenant structures is essentially recommended by dam safety committees [3].

Monitoring of cracks, seepage and other defects in the submerged portion has to be carried out either with the help of divers or by Remote Operated Vehicle (ROV). ROV's are particularly useful to avert unacceptable risk to divers due to environmental (temperature, depth, duration), biological (marine predators, toxic algae), or chemical factors [2]. ROV is used to make the video film of the submerged structure. ROV's are also noticeably cheaper to mobilise and maintain on a project [4]. ROVs are extremely portable and can be flown to any project location. As only 2 team members are required to operate the ROV [5] (a pilot plus a tether technician), it can be on site extremely quickly and cost effectively.

\section{Remote Operated Vehicle for Under Water Monitoring}

The Remote Operated Vehicle (ROV) available with Central Soil and Materials Research Station (CSMRS) (Figure 1) is a sub-sea inspection and observation system, capable of operating down to a depth of $300 \mathrm{~m}$. ROV comprises a Submersible Vehicle, a Surface Control Unit (SCU), an Umbilical Cable connecting the control console to the submersible vehicle, a multimedia recording system, a Video Cassette Recorder(VCR) two video cameras (one DTR $100 \mathrm{Z}$ colour camera and other black and white Silicon Intensified Target (SIT) camera) [6]. It can capture the underwater video and can also be used for underwater scanning of the submerged structure. The Sound Navigation and Ranging (SONAR) system fitted in the ROV is used for navigation aid for obstacle avoidance and to capture acoustic image of the structure. The video signal of underwater object is brought to control console for online viewing and can be recorded in recording system. The black and white camera can operate in very low light intensities. The data is collected and saved in compact disc and video cassette. 


\section{Field Methodology}

The field deployment of ROV involves arrangement of a working platform on the reservoir and power supply for the operation of the instrument. The area to be scanned is marked on the block with reference to the Block No; Reduced Distance (RD) and depth [7]. The vehicle is taken to the desired location with the help of control system. Navigational aid provided by the control system in the form of automatic depth indication and bearing of the vehicle keeps track of the vehicle position. The video film of the scanning work is recorded. Coordinates of distress points are recorded. At the end of the survey, recorded videos is run to see the structural features. The report containing the interpretation and compact discs are handed over to Project Authority.

\subsection{Underwater Scanning of Hirakud Dam Using ROV}

Hirakud dam is a composite structure of earth, concrete and masonry. The main dam having an overall length of $4.8 \mathrm{~km}$, spans between two hills Lamdurgi on left and Chandidurgi on the right. The dam is flanked by $21 \mathrm{~km}$ earthen dykes both on left and right sides to close the low saddles beyond the abutment hills. It has the distinction of being the longest dam in Asia, being $25.8 \mathrm{~km}$ long, with dam and dykes taken together. It has also the rare distinction of forming the biggest artificial lake in Asia with a reservoir spread of $743 \mathrm{sq} . \mathrm{km}$ at full reservoir level. The dam was completed in 1957. This dam has seven turbine units to generate $280 \mathrm{MW}$ power located on the right bank, with $22.4 \mathrm{~km}$ long power channel.

The upstream side is constructed in Ashlar rubble masonry. The inlets of the turbines are covered with trash racks to prevent any floating debris falling into the turbines. The structural arrangement of trash racks generally consist of equally spaced vertical bars supported on horizontal members connected to end vertical members, which rests in the grooves of piers.

The trash racks may be classified into the following types in accordance with their constructional features and the methods of installation as per IS 11388: 2012a [8]) Type 1 Removable section racks which are installed by lowering the sections between side guides or grooves provided in the trash rack structure so that the sections may be readily removed by lifting them from guides. These are generally side bearing type b) Type 2 - Removable section racks in which the individual sections are not installed between guides in the trash rack structure, but are placed adjacent to each other laterally and in an inclined plane to obtain the desired area of flow. Since rack sections may easily be displaced, these have to be secured in place with bolts located above the water line c) Type 3 - Trash rack sections which are bolted in place below water line.

In Hirakud Dam Type -I Trashracks [8] were installed in the intake of Power House area (Figure 2).

\subsection{Diagnosis and Interpretations}

Generally, the concrete/masonry surfaces are intact at all depths. Signs of deterioration/ defect could be seen at few locations. In masonry, the pointing is intact on all over the places where images were captured. The mortar in rubble masonry is not missing in the observed locations. Cracked mortar was not visible. Cavities could not be detected. Algae growth was visible in many places [9] [10]. The concrete portion of the trash racks, that is the slab and columns are generally intact at all depths. Grouting marks could not be observed in the masonry portions. ROV could not be piloted below $530 \mathrm{ft}$ elevation due to wooden debris or other obstructions (Figure $3 \& 4$ ). In front of the trash racks and at the bottom of masonry portion, wooden branches as debris were visible in many places (Figure 3). Heap of stones were found at EL $522 \mathrm{ft}$ inside the trash racks (Figure 4), which is above the invert level of the inlet of the penstock. No other defects were seen in trash racks. The cross section of the horizontal member of the trash rack looks like I section and the vertical member rectangular. In this I section, stones were found lying at many places in the horizontal members (Figure 5) [10].

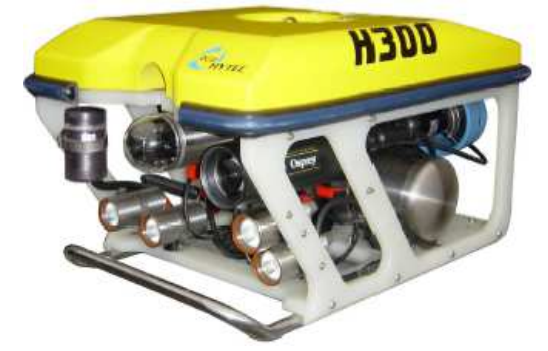

Figure 1. ROV System.

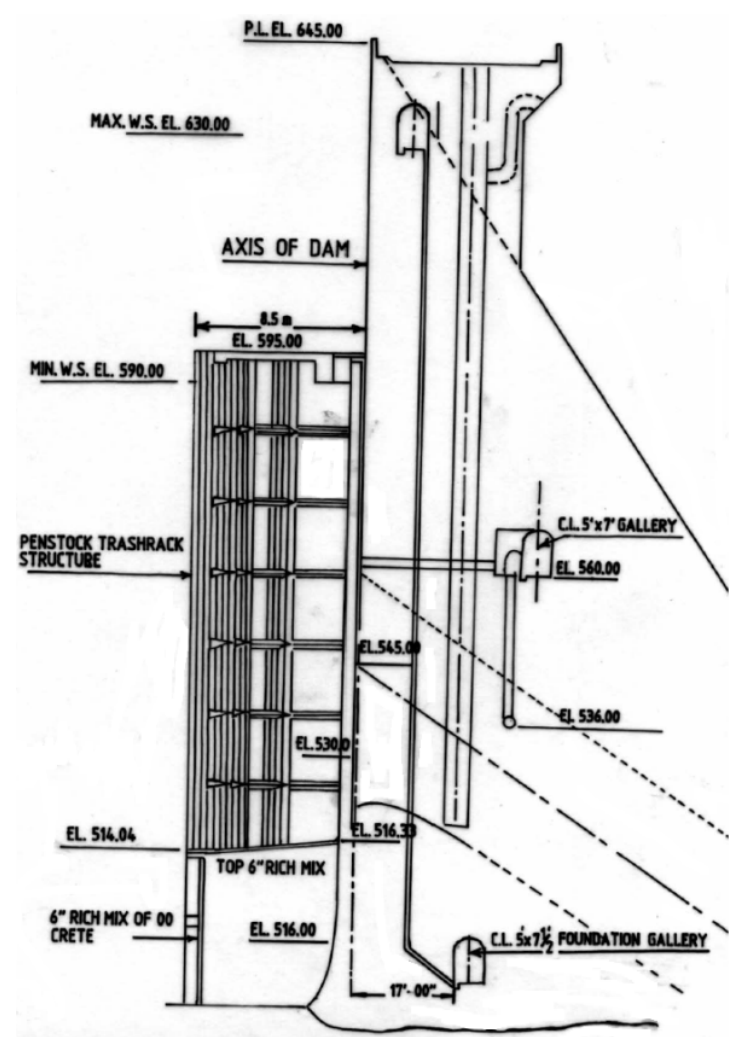

Figure 2. The Cross Section of the Power Intake of Hirakud Dam. 
Due to dense algae growth in all the trash racks except unit 3 and 4, identification of cross section of the vertical members was difficult (Figure $5 \& 6$ ). In the trash rack of unit 3 and 4, mild growth of algae was observed as these were installed recently. Some trash racks of the Unit 4 where almost free of algae growth. Honey combing in concrete was observed at some locations on both banks (Figure $7 \& 8$ ). The observation of the gate grooves revealed anomaly on all gate guides (Figure 9) on the surfaces which are not coming in contact with the rubber seal. From the above images (Figure $7 \& 8$ ), the aggregates used in concrete were found to be rounded indicating the use of river bed material.

No anomaly can be seen on the locations on the gate groove where it comes in contact (Figure 10) with the rubber seal as the portion where the seal is coming in contact with rubber seal of gategroove is always clean and getting good reflections of light (Figure 10). Good concrete could be observed at many locations even at the deepest as well as at the shallowest levels (Figure 12). Previous intact grouting marks could be observed in many locations (Figure 11).

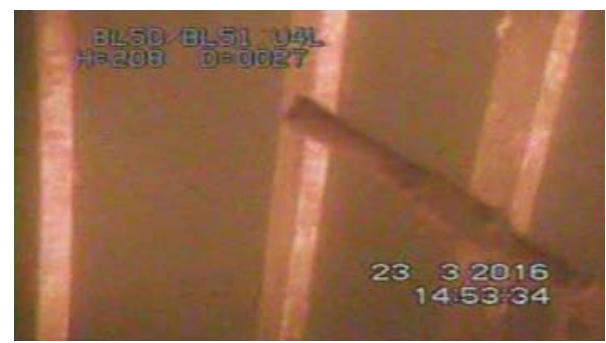

Figure 3. Wooden debris obstructing the downward movement of ROV at EL $528 f t$.

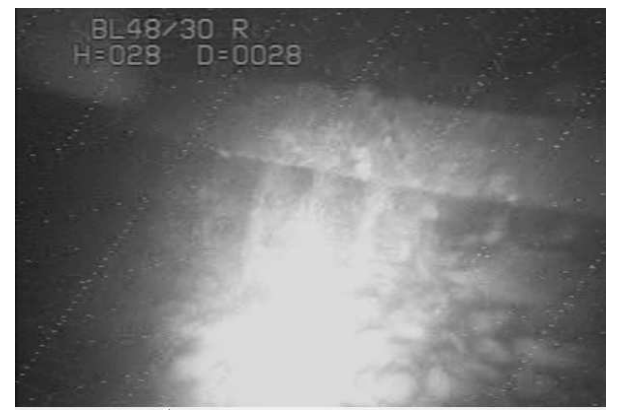

Figure 4. Boulders and pebbles found at EL 522 inside the trash rack of Unit 6.

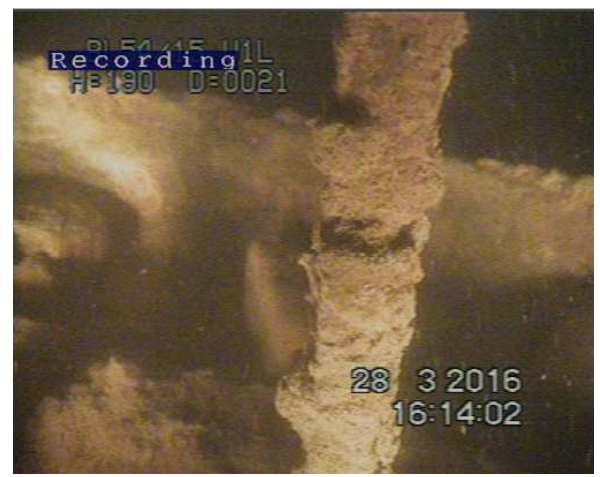

Figure 5. Stones found on horizontal members of left trash racks in Unit 1 at EL547ft.

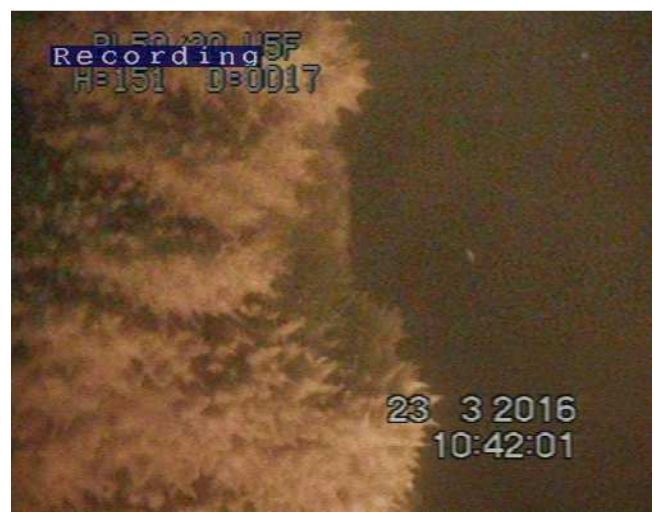

Figure 6. Heavy growth of algae on the vertical members of trash racks of Unit 5 at EL 561ft.

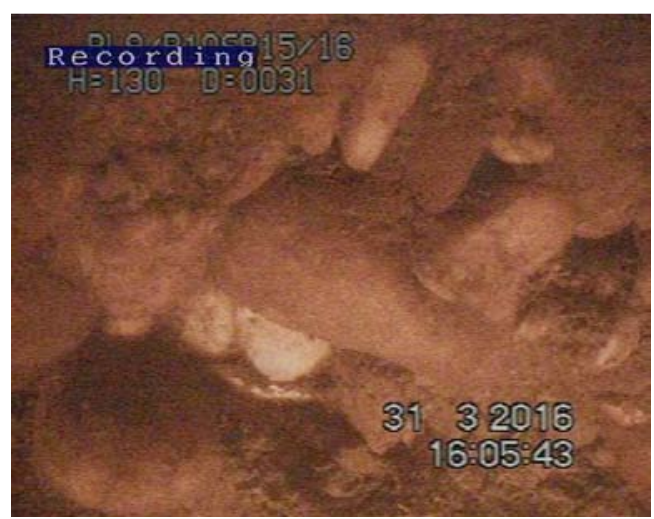

Figure 7. Honey combing in concrete between SB15 and SB16 at EL 513ft.

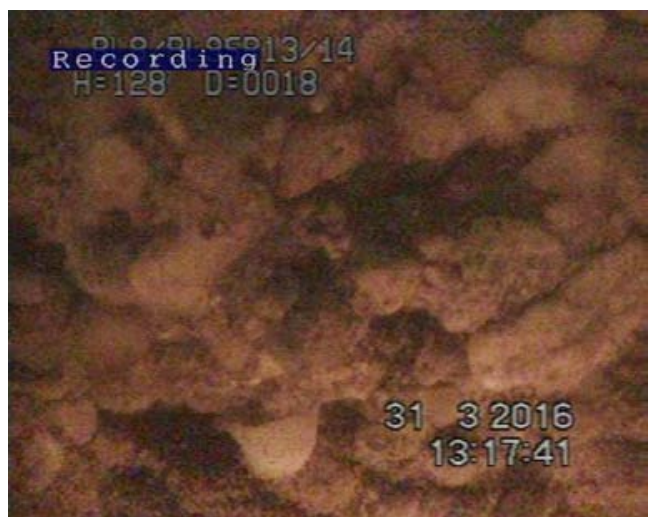

Figure 8. Honey combing in concrete between SB13 and SB14 at EL 556ft.

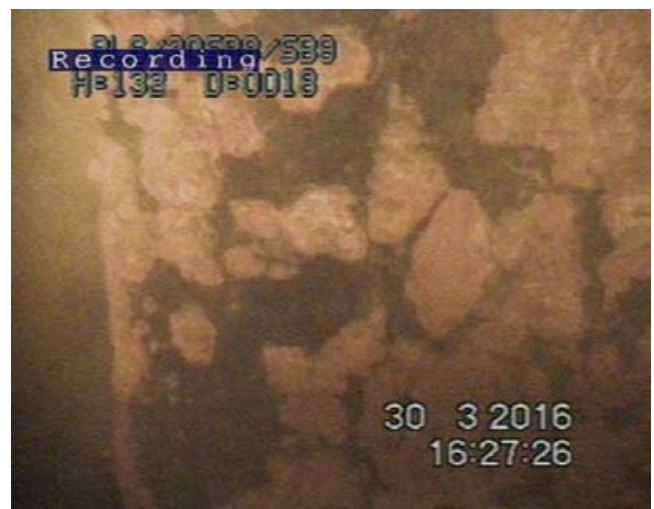

Figure 9. Anomaly on the left gate guide of SB9 at EL $556 \mathrm{ft}$. 


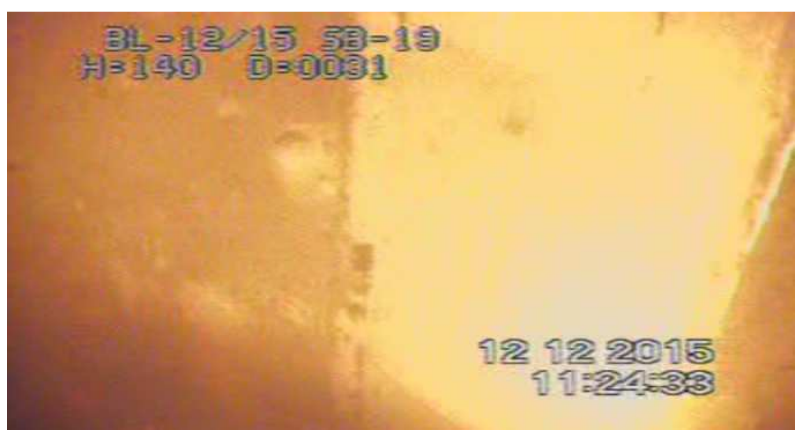

Figure 10. Reflecting portion in gate groove of SB19 at EL523ft.

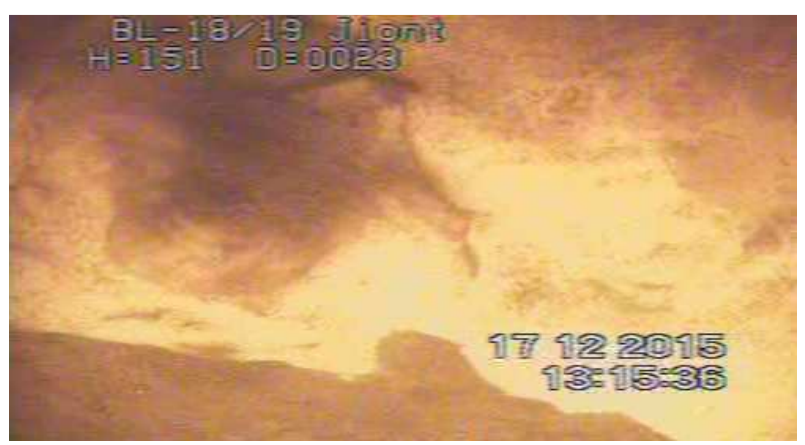

Figure 11. Grouting marks seen at EL549ft. On Block 18/Block 19 Joint.

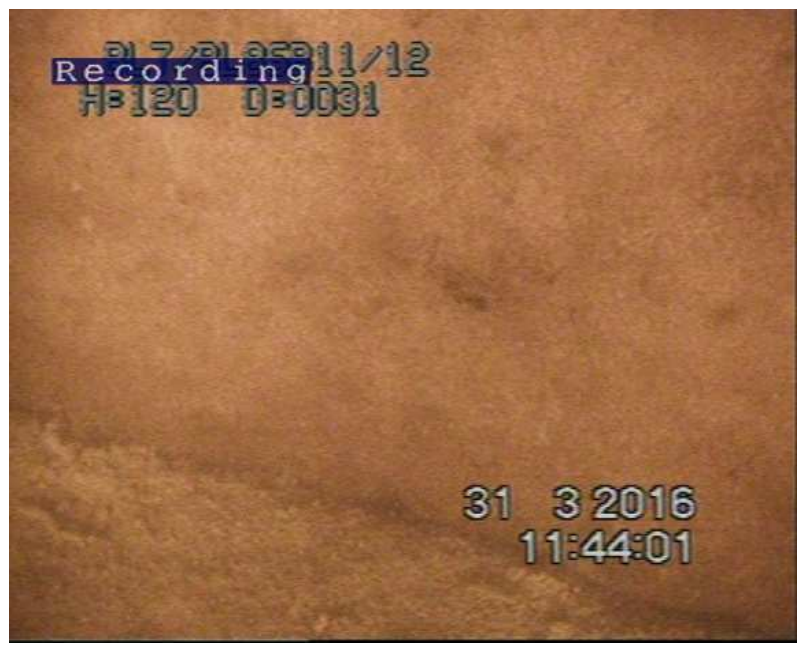

Figure 12. Good concrete at bottom of gate groove of SB 11at EL513ft.

\section{Conclusions}

Generally, the concrete/masonry surfaces are intact at all depths. Signs of deterioration/construction defect could be seen at some places. The grouting marks are seen all over the upstream face at various depths even at an elevation of 507 $\mathrm{ft}$. All grouted areas are intact. Anomaly can be seen on all gate guides only on the surfaces which are not coming in contact with the rubber seal. No anomaly can be seen on the gate groove where it comes in contact with the rubber seal. Construction joints were visible at all locations. The presence of debris above the crest of the power intake was observed and the presences of stones at various heights were also recorded. Thus monitoring of cracks and other defects in the submerged portion carried out with the help of Remote
Operated Vehicle (ROV) proved to be useful. The recorded image can be used for remedial measures of the distressed portion. Scanning of upstream surface must be carried out at regular intervals. Since the debris were found up to the elevation of $530 \mathrm{ft}$ it is recommended to clean the trash racks.

\section{Acknowledgements}

This work was supported by Central Soil and Materials Research Station (CSMRS), New Delhi. Authors wants to thank Director, CSMRS for granting permission to publish this paper. The support extended by investigation team members Dr B. P Singh, NN Singh and Shivcharan are highly acknowledged.

\section{References}

[1] V. Kumar, "Use of Remote Operated Vehicle for Under Water Scanning of Upstream face of Dams and other Hydraulic Structures," in Training Course on Instrumentation in Hydraulic Structures of River Valley Projects, New Delhi, 1999.

[2] T. Yasukazu, I. Hiroshi and I. Yuzuru, "MURS - 300 MK II: A Remote Inspection System for Underwater facilities of Hydraulic Power Plants," IEEE Journal of Ocean Engineering, Vols. OE-II, no. 3, 1986.

[3] A. Varughese, "Application of Remote Operated Vehicle and Geophysical Methods for Diagnostic Investigation of Existing Dams," in Training course on Investigation of Existing Dams on 28th -29th Sep 2015, Dam Rehabilitation and Improvement project, New Delhi, 2015.

[4] A. Varughese, "Diagnostic Investigation of Mullaperiyar Dam using Remote Operated Underwater Vehicle Second National Dam Safety Conference 12-13 January 2016," in Dam Rehabilitation and Improvement project, Bangalore, 2016.

[5] A. Varughese, "Application of Remote Operated Vehicle as a Post Construction Instrumentation for an Existing Dam- A Case Study," ILJTEMAS International Journal of Latest Technology in Engineering, Management \& Applied Science, vol. IV, no. 4, pp. 8-13, 2016.

[6] V. Alex, Haridev and G. S. L., "Application of Remote Operated Vehicle for Diagnostic Investigation of Existing Dams," in National Workshop on Dam Rehabilitation - Trends and Practices, 13-14 October, Pune, 2016.

[7] CSMRS, "Report on Underwater Scanning of the Upstream Face of the Power House Section of Hirakud Dam using Remote Operated Vehicle," New Delhi, 2016.

[8] H300_ROV, "User Manual," M/s Hytec Hydro Technologies, France, 2005.

[9] BIS, IS: 11388, Indian Standard Recommendations for Design of Trash Racks for Intakes, New Delhi: Bureau of Indian Standards, 2012.

[10] CSMRS, Report Underwater Scanning of the Upstream Face of Mullaperiyar Dam Using Remote Operated Vehicle, New Delhi: CSMRS, 2011. 